\title{
Achieving Sustainable Energy in Rural Communities in Ghana
}

\author{
Kwabena Boafo Adom-Opare (Corresponding Author) \\ World Bank - ECREEE ROGEP ${ }^{1}$ \\ One Airport Square, $8^{\text {th }}$ Floor, Airport City, P.O. Box 5374 \\ Cantonment, Accra, Ghana
}

Tel: 233246253 436. E-mail: adomoparekb@gmail.com

Daniel Kweku Baah Inkoom

Kwame Nkrumah University of Science and Technology

Department of Planning, Kumasi, Ghana

E-mail:dinkoom@gmail.com

Received: February 26, 2017 Accepted: March 16, 2017 Published: December 22, 2017

doi:10.5296/jpmr.v3i2.10838 URL: http://dx.doi.org/10.5296/jpmr.v3i2.10838

\begin{abstract}
The paper uses a range of sustainability-measuring indicators to define and measure sustainable energy in a rural context. The use of fuel wood and charcoal in rural areas has consequences on the environment and human health and ultimately, climate change. Fuel wood and charcoal consumption for example pose threats in through carbon emissions. Though Ghana and most African countries are not heavy carbon emitters, it is important to recognize that fuel wood and charcoal are major sources of residential and industrial energy resource. From the study, it was estimated that household and industrial/commercial fuel wood and charcoal consumption, emitted 24,171 tCO2/year and the net carbon capture ${ }^{2}$ was about 112billion tCO2/year. The balance between carbon emitted and capture provides an indication of more room for carbon sequestration in the area and its environs; however high growth in fuel consumption coupled with increasing forest reduction and water evaporation (refer to section 4.6.3 on data on evaporation) presents a case for concern over the years.

\footnotetext{
${ }^{1}$ Current affiliation and World Bank - ECREEE Regional Off-Grid Electrification Project (ROGEP) holds no claims or endorses contents of this work

${ }^{2}$ Here, the forest cover was the only consideration since data on size of soil and water bodies of selected areas were not available from the secondary data.
} 
Keywords: Sustainable Energy, Fuel Wood, Charcoal, Emissions, Rural

\section{Introduction}

Energy, of all kinds, very much stimulates the quality of rural life and consequently, its role in the process of rural development must be emphasized and improved. Having secured access to energy is key to increasing access to water, health care and electricity for businesses and agricultural growth. To appropriately explain the concept of energy security, perhaps, it is best understood when taken literally - 'to be secured in terms of energy supply' (Durante and Sneller, 2005). Several international bodies and energy scholars have wondered around the concept of sustainable energy in a bid to find an appropriate explanation for it. Pandey (2008) defined it as a function of the ability of a nation to satisfy energy needs of current and future generations of all citizens in an affordable manner without adverse impact on the environment and sustainability. While most literature on sustainable energy focuses on energy supply, the demand side is equally important and this paper builds tries to bridge the supply and demand gap in defining sustainable energy. While some literature uses the term energy security, others also prefer the term sustainable energy; for purposes of this paper, both terms are used interchangeably and mean the same.

For the past decade, there have been rising concerns over rural energy needs in developing countries. Often described initially as a situation where biomass fuels were consumed at a rate faster than production and it led to deforestation (Brown et. al., 1988; 1992). Today, energy security has become more difficult as a result of climate change. Practically, rise in sea-levels can be expected to affect prospects of hydro-power generation either positively or negatively (Wilbanks et al., 2008) and the type and frequency of extreme phenomena (as a result of climate change); such as the increase in temperature, flood disasters and droughts can also affect natural forest cover; are expected to rise and have already been observed globally (Mosha, 2011). Some of these impacts are evident in rural areas in Ghana and an example is the increase in the rate of deforestation in most places and evidence of drastic changes in rainfall patterns (Kpeli-Semabia, 2011).

The Intergovernmental Panel on Climate Change [IPCC] (2005) notes that climate change would impact energy supply and demand. Although renewable energy sources may be adaptable to new climate, larger percentages of renewables in Ghana's rural energy supply makes it relatively more vulnerable to climate change (Adom-Opare, 2012). Bio-wood based fuels (example fuel wood and charcoal) and hydropower generation are the energy sources that are most likely to be affected most due to its sensitive nature to the amount, timing, and geographical pattern of precipitation as well as temperature (Thiam, 2009). Reliance on fuel wood and charcoal will either remain at very high levels or even grow over the next few decades (AFREA, 2011; Adom-Opare, 2012).

With projected increasing rural energy demand (Energy Foundation, 2000; Energy Commission, 2012) and anticipated increasing climate change impacts intensity (IPCC, 2009), there is a stimulated need to ensure sustainable energy in rural communities. This paper therefore explores the concept of sustainable energy in a rural context and how it can be 
achieved amidst climate change impacts. It applies models of estimating $\mathrm{CO} 2$ emissions and sustainable energy indices to explore sustainability and climate change in NEMA.

\section{Problem Discussion}

It has become generally accepted that energy supply and demand is a vital component of development but has faced several challenges over time. These challenges which are mainly insufficient supply to meet demand are coupled with population growth, harsh economic factors and today, the impacts of climate change. No state, not even one that is among the strongest, is capable of guaranteeing the complete mitigation of climate change impacts (Mosha, 2011). The situation becomes worse when the impact of climate change is difficult to forecast and the magnitude of uncertainty of the predictive capacity of nations, especially the developing ones, becomes blurring.

Rural communities are faced with unstable supply of energy and in most cases there is lack of access to modern energy services (Thiam, 2009; Adom-Opare, 2012). In rural Ghana, this becomes very disturbing especially when the primary source of energy supply is traditional wood fuel (Energy Commission, 2008; Adom-Opare, 2012). This is alarming because the natural environment from which these energy sources are produced is gradually being damaged by the impacts of climate change.

Evidence of shortages in energy supply is seen in the imbalance between wood-based energy supply and demand in rural Ghana. According to Ghana's 2000-2030 energy outlook report, wood-based fuels yield (WFY) stood about 17 million tones p.a. in 2000, while consumption was at about 19 million tones p.a. In the Nzema East Municipal Assembly (NEMA) where this paper's findings are based, shows a similar case where the average daily fuel wood demand was more than its supply by $17 \mathrm{~kg} /$ day (Adom-Opare, 2012). This phenomenon has been projected to worsen in 2016 and 2020, with WFY reducing considerably while consumptions increase exponentially (Energy Commission, 2012). The reduction in stock of rural energy supply poses a great challenge for rural development and access to energy.

The growing rural populations as well as increase in incomes will trigger high demand for energy (Ghalam, 2008; cited in Wilbanks et al. 2008). It is feared that not only are the levels of energy supply from current sources difficult to achieve but also unsustainable. Hence, sustaining energy for the present and future demand is paramount.

\section{The Rural Concept}

The intricacy in rural studies is that there is no international agreed definition on what a rural or urban area could mean that would be applicable to all countries. For some, "rural" is a subjective state of mind while others see rural as an objective quantitative measure (John, 2008). Several other literatures also define rural by exclusion; that is any other scope under consideration which is not urban-inclined is rural. This school of thought has not gained much currency and not used by most authorities and studies. These notwithstanding, the most agreed upon definition by authors are related to community variations in size and density of population (Dewey, 1960; John, 2008). 
One major criticism was the demographic concept argued by Stewart (1952) is cited in Adom-Opare (2012). He postulates that defining rural or urban areas by demographics will render the idea behind distinguishing the two terms nullified since they apply the same rules of numbers to advanced and developing countries; so that in places where population and land sizes are large the definition of what rural or urban is cannot be used in smaller places due to the difference in population densities. However, the definition of rural and urban communities has still been dominated by their demographics. As John (2008) cited in Adom-Opare (2012) defines it, the concept of can be seen in terms of population and level of facilities available within an area.

About $59 \%$ of populations in developing countries (UN, 2004) are in rural areas. However, since 2004 it has been noted that rural populations are declining due to the general trend of migration to urban areas; example between 2004 and 2010, the world's rural population declined from 59\% to 55.9\% and in Sub-Sahara Africa, it reduced from $64.3 \%$ to $61 \%$ (UN, 2011). Though the populations in rural communities are declining, their energy problems are even now expected to have exacerbated. The increase in urban populations - which is estimated to increase from about $44 \%$ to $60 \%$ by 2030 (World Energy Council, 2004) - is very likely to reinforce policy-makers' preoccupation with urban issues, while increasing competition for rural energy supplies and as a result possible neglect of rural energy needs.

In developing countries, rural communities account for almost $40 \%$ of total energy consumption (Bhagavan and Karekezi, 1992) and it is feared that a large number of rural people might still lack access modern energy in the short to longer terms. The reasons for this may include;

- High cost of grid extension due to long distances and scattered nature of most rural communities

- Low income levels in rural areas to afford modern energy sources

- Non-accessibility of most rural communities and high transport cost (KITE, 2008).

\section{The Concept of Sustainable Energy}

In Sub-Saharan Africa, sustaining energy has become very important as a result of rising concerns of population growth, accelerated urbanization, economic development, climate change, cost and access to fuel, and relative price changes of other energy options (AFREA, 2011; Adom-Opare, 2012). These developments have offset important achievements made in the last decade in energy access, rural electrification, and the promotion of alternative energy sources (Thiam, 2009). A sustainable energy system is needed to speed the economic and social development process and in the long-run achieve sustainable development.

Sustainable energy (SE) just like sustainable development, mean different things and depends on a lot of scenarios to be able to understand the concept (Ogunlade, 2001; Thiam, 2009). Different schools of thought explain the concept of SE differently. In recent times, the search of less carbon-intensive fuels has led some people to perceive SE as pursuing alternative renewable energy sources like solar, wind and mini-hydropower (Ogunlade, 2001). This way 
of viewing SE only defines the concept as using renewable energy sources and is highly advocated by most NGOs (Ogunlade, 2001 cited in Adom-Opare, 2012). This way of definition fails to identify the indicators to use in measuring its sustainability and also fails to properly identify that not all societies have fully developed their renewable energy sources (Adom-Opare, 2012). Another way of understanding the concept is equating SE to energy-efficiency (UNDP, 2000; Energy Commission, 2012; Ogunlade, 2001 cited Adom-Opare, 2012). Here too, it is postulated that improving efficient use of energy can contribute to finding SE. Efficiency used in this view means avoiding energy wastage.

Others however combine efficient energy and renewable energy sources as SE and among them include Renewable Energy and Efficiency Partnership (REEEP) and the Jamaica Sustainable Development Network. Tester et al. (2009) also postulates that SE is achieved through finding new renewable energy sources and maintaining an efficient energy system where there is no or at least little waste through conversion. Some also view SE in terms of whether a country produces or imports oil (Thiam, 2009). It is postulated that in oil producing countries, SE means being able to maintain a position as an energy supplier for the long term, working with stable and low-risk clients and guaranteeing elevated petroleum prices. For those importing oil, SE means being economic and financially stable enough to continually be able to finance importation in the long-run (Thiam, 2009 cited in Adom-Opare, 2012). Understanding the concept of peak oil and the frequent oil crisis and the instability in the Middle East makes one question the whole reliance on this school of thought.

These arguments have led to a much more bipolar perspective of SE that looks at secured supply and improved demand management (Bangaly et al., 1999). In this view also, increasing a secured supply is based on alternative energy sources and diversifying energy sources. That is avoiding dependence on one source of non-renewable energy (oil) but expanding the source base to cover other non-renewables and renewable sources. This will be preceded by awareness-raising actions to promote large scale use. Though a secured supply side is very important, it is not enough to set up a SE framework; the demand management side will need to be included.

The International Energy Agency (IEA) and the Organization for Economic Co-operation and Development (OECD) also argues that energy security can be defined in terms of the physical availability of supplies to satisfy demand at a given price (OECD, 2001). This is rather an accrued way of defining SE since it only stands for physical availability and price (Adom-Opare, 2012). They linked the three pillars of SD with SE in ways that finds out how energy can create an economic, environmental and social sustainable development. Borrowing from the SD indicators, the OECD also used indicators in measuring their defined SE.

Notwithstanding these criticisms, there is a widely used approach which was adopted by the United Nations Development Programme. It describes SE in a more holistic manner and process as compared to the others who move more towards a crude and one side approach based on energy source. It sorts to define SE to cover factors such as the resource endowment, existing energy infrastructure and the development needs of the area in context (Ogunlade, 
2001). Within this context, the UNDP (2000) defined SE as energy that will provide affordable, accessible and reliable energy services that meet economic, social and environmental needs within the overall developmental context of the society while recognizing equitable distribution in meeting those needs. This definition has gained much attention and is used by most energy planners to identify indicators for planning.

This paper defines SE as energy that is affordable, accessible, reliable and equitable for current use without compromising future demand (Adom-Opare, 2012). Hence the variables used in this paper were affordability, accessibility, reliability and equitability; shortened as 'AARE'. This definition includes aspects of spatial and time considerations due to introducing equity to the original definition by the UNDP (Adom-Opare, 2012). The variables are explained in detailed.

\section{Affordability}

This has been explained as the ratio of a household's per capita effective energy consumption to a subsistence threshold. To be able to scientifically measure the affordability in quantifiable terms, the Consumer Energy Burden (CEB) model as used by Power (2008) is adopted and applied. CEB measures the annual percentage of income a household spends on energy utilities and all other residential fuels (Power, 2008). This percentage explains the burden on household wellbeing with reference to how much income is required to pay for residential energy utility. Hence the lower the income, the higher the burden for the same energy bill and though a lower income earner's CEB could be lower than a high income earner's $\mathrm{CEB}$, the burden on the lower income earner is heavier since though they will pay less in terms of percentage (Power, 2008).

\section{Reliability}

How reliable is demand and supply of energy? A question which requires thorough analysis and judgments. In looking at reliability, it is very clear that a number of elements affect its measurements. Some can be quantitative in nature, others are assessed qualitatively (McCarthy et. al., 2008). This variable is measured using the multi-attribute utility theory (MAUT) model. The paper incorporates expert opinion and MAUT into a framework that is extended to include qualitative considerations and applies to other energy sectors and to new energy systems that lack historical performance data (Adom-Opare, 2012). This framework is structured and coded by adequacy and security indices, where adequacy defines to the ability of the energy system to supply customer requirements under normal operating conditions and security defines the dynamic response of the system to unexpected interruptions, and relates its ability to endure them. Together, adequacy and security describe the overall reliability and can be broadly described as the ability to supply (McCarthy et. al., 2008). The indices are explained in annex 1.

\section{Equity}

Finding measures and indices for equity has been a very difficult statistical activity. However, with sound and objective qualitative perceptions and observations, equity could be successfully analyzed. In line with this, the study seeks to define equity as the availability of 
energy source society/household is able to demand. Availability of energy society is able to pay for. It based on qualitative perceptions and observations that equity measurement will be achieved.

\section{$\underline{\text { Accessibility }}$}

Surface accessibility is a term often used in transport and land-use planning, and is generally understood to mean 'ease of reaching'. It is a function of the mobility of the individual, of the spatial location of the opportunities relative to the starting point of the individual, of the times at which the individual is able to participate in the activity and of the times at which the activity is available. That is, the distance covered to reach energy source. Easy physical access to energy demanded. Here, the surface distance to be covered is taken into consideration. The accessibility mapping model used by GTZ and Nkum and Associates (2003) in their programme for rural development is applied. The maximum time, travel speed and waiting time are used extensively in determining the minimum time to cover in order to have access to a particular energy system.

\section{Methods}

A number of statistical models were used in measuring the indicators in the SE framework and the CO2 emission calculator as used by the Cambridge centre for Climate Change (2012). The adopted a model in each indicator measurement and equates them all into the SE framework. Quantitative data were collected for the affordability, accessibility, reliability, time, adaptive capacity and $\mathrm{CO} 2$ emission variables.

For the affordability variable, the Consumer Energy Burden (CEB) model was used. It represents how much "discretionary" income is needed to pay for residential energy year round. From each unit of enquiry, their CEB was calculated by dividing their income by the energy expenditure and finding the percentage of that unit. Aggregation was obtained by their mean. In measuring reliability variable, the model used is discussed in section 4 under the concept of SE. Here a group of 25 experts were interviewed and their perceptions were modelled for this measure. In addition to these perceptions, the MUAT model as used, enhanced for a more quantitative analysis. This model calculated composite scores for the general objectives based upon evaluation of the attributes by the expert panel; this is

summarised below; $U=\sum_{i=1}^{n} w_{i}^{*} u_{t}$

Where $w_{i}$ is the importance weight for attribute $i$ and $u_{i}$ is the utility of attribute $i$, scaled from 0 to 1 (McCarthy et. al., 2008). A Likert scale is applied for this model. Figure 1 shows how the Likert scale was used.

The criteria used in the model are defined table 2.

The paper uses the surface accessibility mapping model/techniques measure the accessibility variable in SE framework and under the time dimension, a series of short, medium to long term projections with the use of Microsoft excel was applied. The adaptive capacity adopted 
the adaptive capacity systems by Smit (2001) cited in Adom-Opare (2012). Here units were asked to rate these determinants using a scale of 1-5, with 1 being the least possible form to support adaptation and 5 being the best form of support to adaptation. Each of these rating sores was divided by 5 to get their ratios for aggregation.

Table 1. Likert scale for Adequacy variable

\begin{tabular}{|c|c|c|c|c|c|}
\hline \multicolumn{3}{|c|}{ Metrics Attributes } & $\begin{array}{c}\text { Primary Source of } \\
\text { supply }\end{array}$ & $\begin{array}{c}\text { Energy } \\
\text { conversion }\end{array}$ & Transport \\
\hline \multirow{6}{*}{ 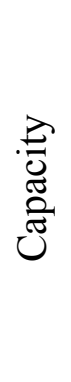 } & \multirow{2}{*}{ Utilisation } & $r_{i}$ & & & \\
\hline & & $w_{i}$ & & & \\
\hline & \multirow{2}{*}{ Intermittency } & $r_{i}$ & & & \\
\hline & & $w_{i}$ & & & \\
\hline & \multirow{2}{*}{ Capacity } & $R$ & & & \\
\hline & & $W$ & & & \\
\hline \multirow{6}{*}{ 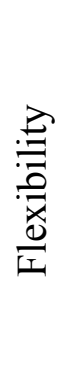 } & \multirow{2}{*}{$\begin{array}{l}\text { Response to demand } \\
\text { fluctuations }\end{array}$} & $r_{i}$ & & & \\
\hline & & $w_{i}$ & & & \\
\hline & \multirow{2}{*}{ Ability to expand facilities } & $r_{i}$ & & & \\
\hline & & $w_{i}$ & & & \\
\hline & \multirow{2}{*}{ Flexibility } & $R$ & & & \\
\hline & & $W$ & & & \\
\hline & ADEQUACY & $R$ & & & \\
\hline
\end{tabular}

Source: Adom-Opare, 2012

Table 2. Criteria for reliability ratings

\begin{tabular}{|c|c|c|c|c|c|}
\hline 0 & 1 & 2 & 3 & 4 & 5 \\
\hline $\begin{array}{c}\text { Indicates that } \\
\text { under no } \\
\text { circumstances } \\
\text { will the } \\
\text { component } \\
\text { operate } \\
\text { intermittently }\end{array}$ & $\begin{array}{c}\text { Indicates that, } \\
\text { given } \\
\text { sufficient } \\
\text { inputs, the } \\
\text { component } \\
\text { will operate } \\
\text { with low } \\
\text { levels of } \\
\text { predictable } \\
\text { intermittency }\end{array}$ & $\begin{array}{c}\text { Please } \\
\text { use your } \\
\text { discretion }\end{array}$ & $\begin{array}{c}\text { Indicates that, } \\
\text { given sufficient } \\
\text { inputs, the } \\
\text { component will } \\
\text { operate with } \\
\text { relatively high } \\
\text { levels of } \\
\text { predictable } \\
\text { intermittency }\end{array}$ & $\begin{array}{c}\text { Please } \\
\text { use your } \\
\text { discretion }\end{array}$ & $\begin{array}{c}\text { Indicates that, } \\
\text { given sufficient } \\
\text { inputs, the } \\
\text { component will } \\
\text { operate with } \\
\text { high levels of } \\
\text { unpredictable } \\
\text { intermittency }\end{array}$ \\
\end{tabular}

Source: Adom-Opare, 2012

In calculating the carbon emissions from fuel wood and charcoal the following equations were used. 
- Emissions factor for Fuel wood $(\operatorname{wood} \operatorname{logs})=0.382 \mathrm{tCO} 2 / \mathrm{kWh}$

- $\quad$ Emissions factor for Charcoal $=0.018 \mathrm{tCO} 2 / \mathrm{kWh}$

- Carbon footprint calculations

Emissions $(\mathrm{tCO} 2 /$ year $)=$ Per capita energy demand (kWh/person-year) $x$ Population (persons) $\mathrm{x}$ Emissions Factor $(\mathrm{tCO} 2 / \mathrm{kWh})$

In calculating the carbon capture/sequestration, the following methodology was used;

- $\quad$ Capture and Sequestration Sinks

Rate of movement from air to vegetation $(\mathrm{tCO} 2 / \mathrm{yr})=\sum$ Net Primary Productivity-NPP $(\mathrm{tCO} 2 / \mathrm{m} 2 / \mathrm{yr}$ or $\mathrm{gC} / \mathrm{m} 2 / \mathrm{yr}) \times$ Area $(\mathrm{m} 2)$

Equations 1 and 2 were used in calculating the carbon footprints and sequestration respectively (Adom-Opare, 2012).

\section{Data and Analysis}

This section of the analysis starts by estimating the CO2 emissions in rural NEMA and then moves towards finding the quantitative measures for the SE framework. It concludes by equating all these variables to finding answers and explanations to the question of sustainable energy in rural communities in Ghana.

\subsection{Carbon Emissions: Rural Contribution}

It is very clear that no technology for energy production or its conversion is innocent without producing a by-product/waste (Adom-Opare, 2012). As a result, most literature on energy have argued for a more renewable energy alternative to fossil fuels and championed the use of water, wind, biomass among others. But, given that currently over a third of the world's population rely on fuel wood and charcoal (Thiam, 2009; REEEP, 2011; Adom-Opare, 2012), there is also the fear of carbon waste emissions. Although fuel wood and charcoal are renewable and are highly recommended, this cannot be taken for granted; as the amount of carbon emitted from such mass fuel consumption is often unnoticed. Often such renewables are regarded as environmentally and socially beneficial, unfortunately, it is not intrinsic in biomass energy, but dependent on "site- and fuel cycle-specific factors" (Hall and Scrase, 1998).

\subsubsection{Calculating Fuel wood and Charcoal Carbon Emissions}

Against this backdrop, the carbon emissions are calculated in all the selected communities and this is done based on the various zones identified - moist deciduous zone, secondary forest zone and coastal savannah zone - as well as pertaining to the whole study area. Based on the data collected both secondary and primary, the computation is as follows;

\section{Population Figures}

Total population $=$ number of households $(90) \times$ average household size (6.21) 
$=558.9$ (approximately 559)

2. Conversion from $\mathrm{kg}$ to $\mathrm{kWh}$ [Conversion units by Quaschning, 2012]

$1 \mathrm{~kg}=8.14 \mathrm{kWh}$

\section{Calculations}

\section{I: Fuel Wood}

Energy Demand:

Fuel wood demand per day $=193.3 \mathrm{~kg}$

Conversion into $\mathrm{kWh} \quad=193.3 \mathrm{~kg} / 1 \mathrm{~kg} \times 8.14 \mathrm{kWh}$

$$
=1,573.5434 \mathrm{kWh}
$$

Fuel wood demand per annum (356days) $=878.5502 \mathrm{kWh}$ x 356days

$$
=560,181.45 \mathrm{kWh} / \mathrm{yr}^{3}
$$

- $\quad$ Moist Deciduous $\quad=231,466.98 \mathrm{kWh} / \mathrm{yr}(41.32 \%)$

- Secondary $\quad=143,742.56 \mathrm{kWh} / \mathrm{yr}(25.66 \%)$

- Coastal Savannah $\quad=185,980.24 \mathrm{kWh} / \mathrm{yr}(33.02 \%)$

Emissions from Fuel wood

$560,181.45 \mathrm{kWh}^{4} / \mathrm{yr} \times 0.018 \mathrm{tCO} 2 / \mathrm{kWh}=\underline{\underline{\mathbf{1 0}, 083.27} \text { tCO2/year }}$.

- Moist Deciduous $\quad=4,166.41 \mathrm{tCO} 2 /$ year

- Secondary $\quad=2,587.37 \mathrm{tCO} 2 /$ year

- Coastal Savannah $=3,347.64 \mathrm{tCO} 2 /$ year

\section{II: Charcoal}

Energy Demand: Charcoal

Charcoal demand per day $\quad=13.22 \mathrm{~kg}$

Conversion into $\mathrm{kWh} \quad=13.22 \mathrm{~kg} / 1 \mathrm{~kg} \times 8.14 \mathrm{kWh}$

$$
=107.61 \mathrm{kWh}
$$

Charcoal demand per annum (356days) $\quad=107.61 \mathrm{kWh} \times 356$ days

$$
=38,309.16 \mathrm{kWh} / \mathrm{yr}^{5}
$$

- $\quad$ Moist Deciduous $=9,473.86 \mathrm{kWh} / \mathrm{yr}(24.73 \%)$

\footnotetext{
${ }^{3}$ The total energy demand per year already includes the total population (in that Energy/population: per person multiplied by population leads to energy demand)

4 Refer to 1

5 Refer to 1
} 
- Secondary $\quad=20,112.31 \mathrm{kWh} / \mathrm{yr}(50.25 \%)$

- $\quad$ Coastal Savannah $\quad=9,584.95 \mathrm{kWh} / \mathrm{yr}(25.02 \%)$

Emissions from Charcoal

$38,309.16 \mathrm{kWh} / \mathrm{yr}^{6} \times 0.382 \mathrm{tCO} 2 / \mathrm{kWh}=\underline{\underline{\mathbf{1 4}, 634.10 \text { tCO2} / \text { year }}}$.

- Moist Deciduous = $=3,619.01 \mathrm{tCO} 2 /$ year

- Secondary $\quad=7,682.90 \mathrm{tCO} 2 /$ year

- Coastal Savannah $=3,661.43 \mathrm{tCO} 2 /$ year

From (1) and (2), the total carbon footprint of the community from fuel wood and charcoal is

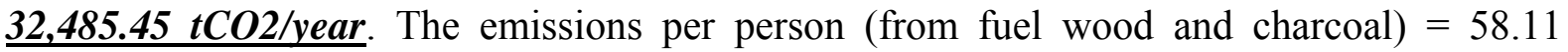
tCO2/year.

Even though charcoal per capita consumption is low compared to fuel wood, its effects on climate change are high due to the emissions factor. Therefore if measures are not in place to efficiently use charcoal; via proper improved end use equipment, carbon emissions could be very high in charcoal consumption. Though these emissions cannot be compared to that of the carbon emitted via fossil fuels, it is still important identify and understand the contributions of fuel wood and charcoal to the emission mix in Ghana since majority of the population use these energy forms.

High energy demand or consumption does not necessarily mean or produces high emissions. The determining factor is the type of energy being used and the corresponding emission factors, in other words the demand for fuel wood is approximately four times as much as charcoal, however the emissions is the reverse. When the carbon emissions are compared to the various income groups in the sampled households, it is realised that there was strong positive correlation $(r=0.85)$ between higher incomes groups and higher per capita carbon emissions. This implies that, households with higher incomes consume more fuels and thus the higher carbon emissions.

\section{$\underline{\text { Net Primary Production Calculation (Sequestration) }}$}

It is important to identify how the natural environment sequestrates these emissions. The net primary production is the rate at which all the plants in an ecosystem produce net useful chemical energy; it is equal to the difference between the rate at which the plants in an ecosystem produce useful chemical energy (GPP) and the rate at which they use some of that energy during respiration. Both the gross and net primary productions are in units of mass/area/time. In terrestrial ecosystems, mass of carbon per unit area per year $\left(\mathrm{gC} / \mathrm{m}^{2} / \mathrm{yr}\right)$ is most often used as the unit of measurement. The carbon sink calculation is as follows (the same methodology as in the carbon emissions calculation is applied here);

- $\quad$ Capture and Sequestration Sinks

\footnotetext{
${ }^{6}$ Refer to 1
} 
Rate of movement from air to vegetation $(\mathrm{tCO} 2 / \mathrm{yr})=\sum$ Net Primary Productivity-NPP $\left(\mathrm{tCO} 2 / \mathrm{m} 2 / \mathrm{yr}\right.$ or $\left.\mathrm{gC} / \mathrm{m}^{2} / \mathrm{yr}\right) \times$ Area $(\mathrm{m} 2)$

- $\quad$ Net Primary Productivity (NPP) of Tropical Forests $=925 \mathrm{gC} / \mathrm{m}^{2} / \mathrm{yr}$

- $\quad$ Conversion from acres to square meters

lacre $=4046.856 \mathrm{~m}^{2}$; the forest cover of the study area is considered here.

$$
\begin{gathered}
30,000 \text { acres }=30,000 \times 4,046.856 \mathrm{~m}^{2} \\
=121,405,680 \mathrm{~m}^{2}
\end{gathered}
$$

\section{- Calculations}

Carbon sink

$$
\begin{aligned}
= & 925 \mathrm{gC} / \mathrm{m}^{2} / \mathrm{yr} \times 121,405,680 \mathrm{~m}^{2} \\
= & 112,300,254,000 \mathrm{tCO} 2 / \mathrm{yr} \\
& \approx \mathbf{1 1 2 b i l l i o n} \mathbf{t C O 2} / \mathbf{y r}
\end{aligned}
$$

It should be said here that, though the carbon sink is a measurement of capture, it is only a crude way of indicating how the situation looks like as it is very difficult to segregate carbon in the atmosphere; notwithstanding, it provides some indications for decision making. Hence comparing the sink value (112billion tCO2/yr) to the emission value $(32,485.45 \mathrm{tCO} 2 /$ year), it is seen that, there is more room for carbon emission based on charcoal and fuel wood only. However, this is never the case as carbon emission was not accounted for from other energy and non-energy sources in the case area. But what is clear here is that, even with the fuel wood and charcoal alone, the carbon emitted is still quite large for the forest; which also acts as a sink for other geographic area's carbon emissions; as it takes years for trees to mature enough to capture carbon in the atmosphere.

\subsection{Sustainable Energy: Equating the indicators}

Sustainable energy (SE) is a complex notion which can be "unpacked" in different ways; and it becomes more complex when the various energy forms are put together. No single measurement tells the whole story even for one energy form, let alone for more than one. If overall these are indicators are moving in the right direction, then we can say that sustainable energy is improving (or vice versa). Some of the indicators may enable us to say that SE has been achieved for certain groups. Each of the indicators will be analysed in this section.

\section{Affordability}

Using the CEB tool to determine how affordable energy is to the various units of enquiry, the CEB tool simple means, measuring the ability to pay for necessary levels of consumption within normal spending patterns for both fuel wood and charcoal. The CED is expressed as a percentage of income used to pay energy bills (Economic Opportunity Studies, 2012). 


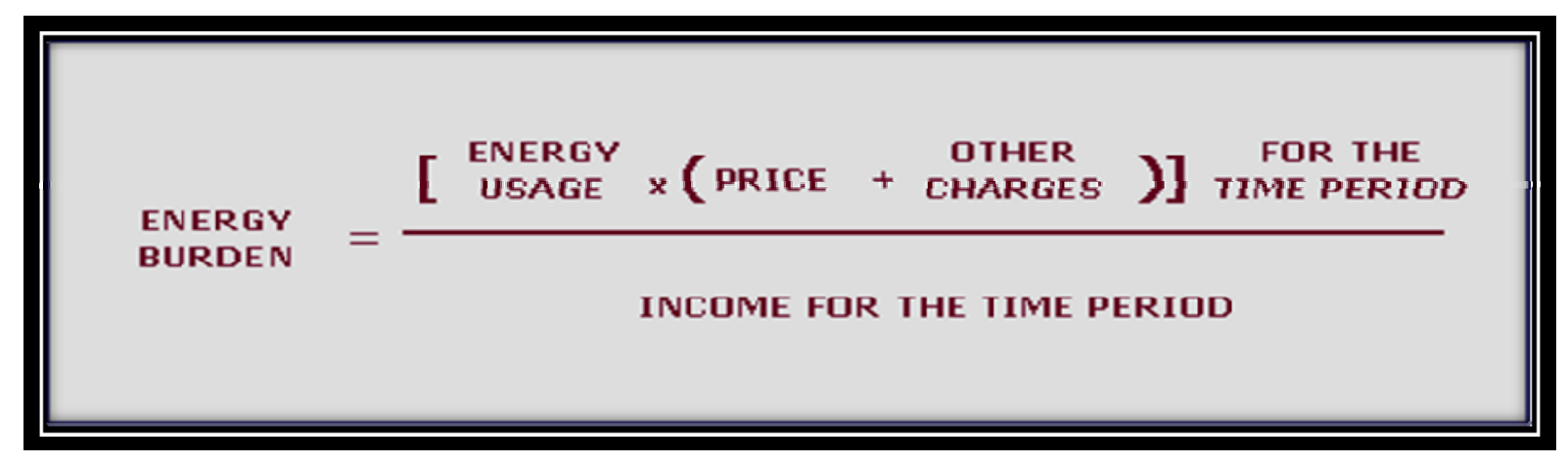

Figure 1: Model for Energy Burden calculation

Source: Economic Opportunity Studies, 2012

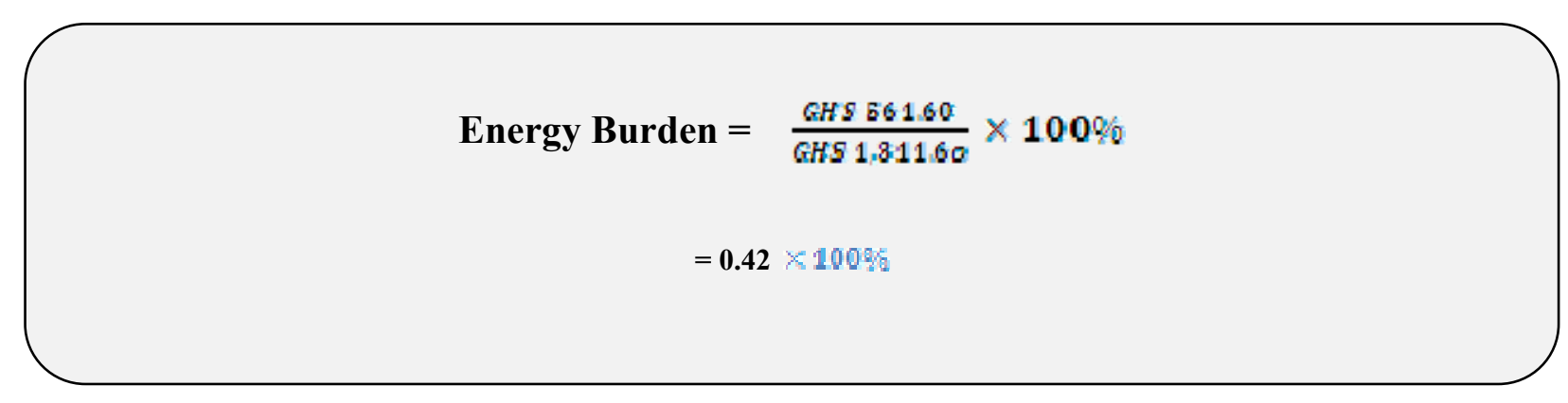

Figure 2: Energy Burden computation ${ }^{7}$

Source: Adom-Opare, 2012

The model explains that, the lower the income, the higher the burden for the same energy expenditure, and so invariably, a higher CEB explains an unaffordable energy forms. This scenario is not a positive indicator in the sustainable energy framework. From the Energy Burden calculation above, a CEB of $42 \%$ represents a high burden and it could be said that, energy is not affordable based on the module and indicators used.

\section{$\underline{\text { Accessibility }}$}

Accessibility here is not concerned with quality and number of activity but with the opportunity provided by the transport and land-use system. Hence it will be considered as the percentage of time that a particular energy source is available for use and a less percentage of damage to the environment as a result of access. Number of assumptions were used here; (1) it is assumed that here, the only mode of travel to energy sources is by walking, and (2) it is assumed that foot paths are class 3 access routes (when the accessibility map module is used). These assumptions are as a result from the findings from the study which showed most of the energy suppliers walked to their farms and used a certain type of foot path.

The average distance covered to have access to fuel wood is $4.5 \mathrm{~km}$; and out of this majority $(52 \%)$ were obtained outside the various communities selected. It was also realised that, over the past 5 to 10 years, the distance covered to have access to fuel wood had been increasing. The picture here is that, the increase in consumption is affecting the forest resources in these

\footnotetext{
7 The average monthly income and expenditures of energy are detailed in Annexes 2-4
} 
communities and resulting in consumers walking longer distances $(4.5 \mathrm{~km})$ to obtain wood for fuel.

Using surface accessibility model, the standard maximum travel times to access facilities is used in the computation of the access zones are done. Table 3 shows the maximum travel times in each access zone based on model.

Tale 3. Accessibility Standards with respect to Travel time (in minutes)

\begin{tabular}{ccccc}
\hline \multirow{2}{*}{ Facility } & $\begin{array}{c}\text { High access } \\
\text { zone }\end{array}$ & $\begin{array}{c}\text { Medium access } \\
\text { zone }\end{array}$ & $\begin{array}{c}\text { Low access } \\
\text { zone }\end{array}$ & $\begin{array}{c}\text { Least access } \\
\text { zone }\end{array}$ \\
\hline Agriculture $^{8}$ & Up to 25 & $25-35$ & $35-40$ & More than 40 \\
\hline
\end{tabular}

Source: GTZ, 2007

Based on the accessibility standards, an average of walking to access agriculture facilities is $4 \mathrm{~km} / \mathrm{hr}$ and used in this context. Travelling by foot to the farms to access fuel wood along foot paths at $4 \mathrm{~km} / \mathrm{hr}$, the maximum distance that one can travel to be in a high access zone within 25 minutes is calculated as;

$$
\begin{gathered}
60 \text { minutes }=4 \mathrm{~km} \\
\frac{25}{60} \times 4 \mathrm{~km}
\end{gathered}
$$

This implies that, all those who are within $1.9 \mathrm{~km}$ away from their farms can access fuel wood within 25 minutes and are classified as within the high access zone. This computed in the same way for all the other access zones. Table 4 below shows the summary of results as well as percentage of the population within each access zone.

Table 4. Access zones and population within each access zone

\begin{tabular}{cccccccc}
\hline \multicolumn{2}{c}{ High access zone } & \multicolumn{2}{c}{ Medium access zone } & \multicolumn{2}{c}{ Low access zone } & \multicolumn{2}{c}{ Least access zone } \\
\hline $\begin{array}{c}\text { Distance } \\
(\mathrm{km})\end{array}$ & $\begin{array}{c}\% \text { of } \\
\text { population }\end{array}$ & $\begin{array}{c}\text { Distance } \\
(\mathrm{km})\end{array}$ & $\begin{array}{c}\text { \% of } \\
\text { population }\end{array}$ & $\begin{array}{c}\text { Distance } \\
(\mathrm{km})\end{array}$ & $\begin{array}{c}\% \text { of } \\
\text { population }\end{array}$ & $\begin{array}{c}\text { Distance } \\
(\mathrm{km})\end{array}$ & $\begin{array}{c}\% \text { of } \\
\text { population }\end{array}$ \\
\hline 1.7 & 34 & 2.4 & 5 & 2.7 & 10 & 3.2 & 41 \\
\hline
\end{tabular}

Source: Adom-Opare, 2012

The accessibility analysis summarised in the table above shows that majority $(51 \%)$ of the sampled households are within the low (10\%) and least (41\%) access zones to fuel wood as is confirmed by the average distance $(4.5 \mathrm{~km})$ covered to access fuel wood. This condition is not favourable under the sustainable energy framework since majority are in the low access zones, and this distance covered to access energy is increasing rapidly.

\section{$\underline{\text { Reliability }}$}

\footnotetext{
8 Agriculture is used because more than $97 \%$ of sampled households obtain fuel wood from their farms
} 


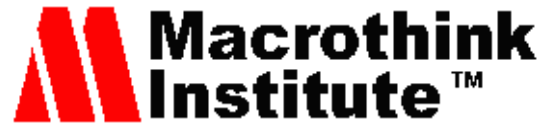

Journal of Public Management Research

ISSN 2377-3294

2017, Vol. 3, No. 2

Table 5. Average utility and importance ratings and aggregated concept and general objective reliability indices for adequacy

\begin{tabular}{|c|c|c|c|c|c|}
\hline \multicolumn{3}{|c|}{ Functional Zones Attributes } & $\begin{array}{c}\text { Primary Source of } \\
\text { Supply }\end{array}$ & $\begin{array}{c}\text { Energy } \\
\text { Conversion }\end{array}$ & Transport \\
\hline \multirow{6}{*}{ 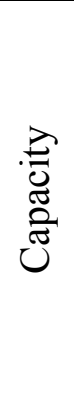 } & \multirow{2}{*}{ Utilisation } & $r_{i}$ & 0.50 & 0.35 & 0.65 \\
\hline & & $w_{i}$ & 1.00 & 0.80 & 0.80 \\
\hline & \multirow{2}{*}{ Intermittency } & $r_{i}$ & 0.60 & 0.55 & 0.45 \\
\hline & & $w_{i}$ & 0.80 & 0.60 & 0.60 \\
\hline & \multirow{2}{*}{ Capacity } & $R_{c i}$ & 0.55 & 0.45 & 0.55 \\
\hline & & $W$ & 0.90 & 0.70 & 0.70 \\
\hline \multirow{6}{*}{ 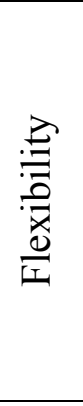 } & \multirow{2}{*}{$\begin{array}{l}\text { Response to demand } \\
\text { fluctuations }\end{array}$} & $r_{i}$ & 0.45 & 0.46 & 0.65 \\
\hline & & $w_{i}$ & 0.40 & 0.60 & 0.80 \\
\hline & \multirow{2}{*}{ Ability to expand facilities } & $r_{i}$ & 0.85 & 0.66 & 0.25 \\
\hline & & $w_{i}$ & 0.20 & 0.40 & 0.60 \\
\hline & \multirow{2}{*}{ Flexibility } & $R_{f i}$ & 0.65 & 0.56 & 0.45 \\
\hline & & $W$ & 0.30 & 0.50 & 0.70 \\
\hline \multicolumn{2}{|r|}{ ADEQUACY } & $R_{i}$ & \multicolumn{3}{|c|}{0.54} \\
\hline
\end{tabular}

Source: Adom-Opare, 2012

NB: Scores of 1 represent the worst reliability rating (u) and the highest important rating (w), while 0 corresponds to high reliability or low importance.

The results from table 5 shows that, the experts perceive conversion and transportation of fuel wood and charcoal offers some level of adequacy by the capacity to provide sufficient supply to final demand and the flexibility to adapt to volume and geographical fluctuations in demand. However, under the primary source of supply, the flexibility to adapt to fluctuations to changes in demand volumes negatively affects adequacy of fuel wood and charcoal; reflected by a high utility score of $R_{f i}=0.65$. It was also realised that, the experts regard utilization as the most important attribute to include in reliability issues under adequacy, across all three (3) functional areas; they rate its importance at $\mathrm{W}=0.9$. However, the experts showed that, all the attributes were important enough to be included as the least weight given to the attributes was 0.5 .

In the case of security (in table 6 above), The model shows that the large availability of forest cover and the good history of fuel wood and charcoal conversion rates, greatly improves security of primary energy supply and energy conversion (with average security utility scores of 0.20 and 0.25 for physical security and history respectively) over the other attributes, which are more difficult to secure. The views of global influence on local fuel wood and charcoal supply source, conversion and transportation are very minimal and does not heavily affect local conditions. 


\section{Ml Macrothink}

Journal of Public Management Research

ISSN 2377-3294

2017, Vol. 3, No. 2

Table 6: Average utility and importance ratings and aggregated concept and general objective reliability indices for security

\begin{tabular}{|c|c|c|c|c|c|}
\hline \multicolumn{3}{|c|}{ Functional Zones Attributes } & $\begin{array}{l}\text { Primary Source } \\
\text { of supply }\end{array}$ & $\begin{array}{c}\text { Energy } \\
\text { conversion }\end{array}$ & Transport \\
\hline \multirow{10}{*}{ 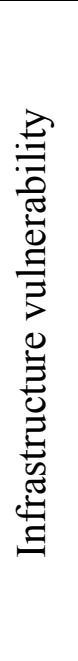 } & \multirow{2}{*}{ Physical security } & $r_{i}$ & 0.20 & 1.00 & 0.00 \\
\hline & & $w_{i}$ & 0.64 & 0.82 & 0.43 \\
\hline & \multirow{2}{*}{ Interdependencies } & $r_{i}$ & 0.60 & 0.80 & 0.60 \\
\hline & & $w_{i}$ & 0.62 & 0.80 & 0.40 \\
\hline & \multirow{2}{*}{ Sector coordination } & $r_{i}$ & 0.85 & 0.60 & 0.40 \\
\hline & & $w_{i}$ & 0.21 & 0.42 & 0.22 \\
\hline & \multirow{2}{*}{ History } & $r_{i}$ & 0.81 & 0.25 & 0.63 \\
\hline & & $w_{i}$ & 0.43 & 0.63 & 0.80 \\
\hline & \multirow{2}{*}{ Infrastructure vulnerability } & $R_{v i}$ & 0.60 & 0.60 & 0.40 \\
\hline & & $W$ & 0.50 & 0.70 & 0.50 \\
\hline \multirow{8}{*}{ 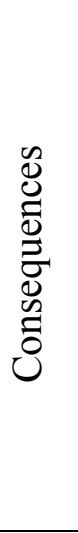 } & \multirow{2}{*}{ Economic impacts } & $r_{i}$ & 0.63 & 0.40 & 0.63 \\
\hline & & $w_{i}$ & 0.60 & 1.00 & 0.64 \\
\hline & \multirow{2}{*}{ Environmental impacts } & $r_{i}$ & 0.97 & 0.80 & 0.25 \\
\hline & & $w_{i}$ & 1.00 & 1.00 & 1.00 \\
\hline & \multirow{2}{*}{ Human health impacts } & $r_{i}$ & 0.45 & 0.85 & 0.22 \\
\hline & & $w_{i}$ & 0.81 & 1.00 & 1.00 \\
\hline & \multirow{2}{*}{$\begin{array}{c}\text { Consequences of } \\
\text { infrastructure disruption }\end{array}$} & $R_{d i}$ & 0.68 & 0.65 & 0.30 \\
\hline & & $W$ & 0.80 & 1.00 & 0.90 \\
\hline \multirow{8}{*}{ 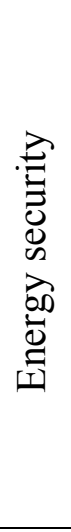 } & \multirow{2}{*}{ Import levels } & $r_{i}$ & $\mathrm{~N} / \mathrm{A}$ & 0.90 & $\mathrm{~N} / \mathrm{A}$ \\
\hline & & $w_{i}$ & $\mathrm{~N} / \mathrm{A}$ & 0.14 & N/A \\
\hline & \multirow{2}{*}{$\begin{array}{l}\text { World excess production } \\
\text { capacity }\end{array}$} & $r_{i}$ & N/A & N/A & N/A \\
\hline & & $w_{i}$ & N/A & N/A & N/A \\
\hline & \multirow{2}{*}{ Price volatility } & $r_{i}$ & 0.21 & 0.20 & 0.63 \\
\hline & & $w_{i}$ & 0.61 & 0.61 & 0.72 \\
\hline & \multirow{2}{*}{ Energy security } & $R_{e i}$ & 0.50 & 0.50 & 0.50 \\
\hline & & $W$ & 0.43 & 0.40 & 0.40 \\
\hline \multicolumn{2}{|r|}{ SECURITY } & $R_{i}$ & \multicolumn{3}{|c|}{0.53} \\
\hline
\end{tabular}

Source: Adom-Opare, 2012

From the model so far, the expert panel perceives that energy conversion and transport may improve reliability in fuel wood and charcoal supply (from both the adequacy and security attributes). On average, the experts rated these two functional zones as more reliable than the 
primary source of supply source; with average utility scores for adequacy $=0.50$ and average utility scores for security $=0.49$; which means it is perceived that current energy mix is more secured than adequate.

Even though one cannot accurately predict a quantitative forecast into the future with these models, the scores nonetheless provide a clear enough picture to conclude that these experts perceive the likely unreliability of fuel wood and charcoal supply in terms of the attributes selected.

\section{$\underline{\text { Equity }}$}

The study showed a clear disparity in physical and economic access to energy sources in NEMA; with Axim and its environs which form the coastal savannah zone, having access to all facilities available in NEMA, the secondary forest zone and the moist deciduous zones are not able to access such energy facilities. It was realized that, due to lack of physical access in most parts of the year, inhabitants in this zone consume very less charcoal compared to those in the other zones. The main attribute was the poor nature of roads in this zone. This shows an unfavorable measure under the sustainable energy framework indicator.

\section{Spatial Dimension}

Three distinct spatial locations were carved from NEMA as part of this study; deciduous forest, secondary forest and coastal savannah zones.

It was realised that while the deciduous forests (located in the northern parts), were covered with large forest cover and with plenty energy resources, the coastal savannah zone (located in the southern or coastal belts) was limited to few forest resources from which they could have access to energy sources (fuel wood and charcoal tree species). The intermediate secondary forests (centrally located) were seen with some forest covers however not as much as compared to the northern parts. This translates into how much energy the locations were consuming.

Table 7. Daily quantity and daily expenditure on fuel wood and charcoal among different zones

\begin{tabular}{ccccc}
\hline \multirow{2}{*}{ Zones } & \multicolumn{2}{c}{ Fuel wood } & \multicolumn{2}{c}{ Charcoal } \\
\cline { 2 - 5 } & Quantity (kg) & Amount Spent (GHS) & Quantity (kg) & Amount Spent (GHS) \\
\hline Northern & 14.0 & 0.45 & 2.0 & 1.5 \\
Central & 9.1 & 0.47 & 4.1 & 0.6 \\
Southern & 11.5 & 0.82 & 2.0 & 0.8 \\
\hline
\end{tabular}

Source: Adom-Opare, 2012

As can be seen, the northern zone spent more and consumed of fuel wood and charcoal resources as compared to the other zones. The explanation that was attributable to this was the access and availability of these resources to consumers. 


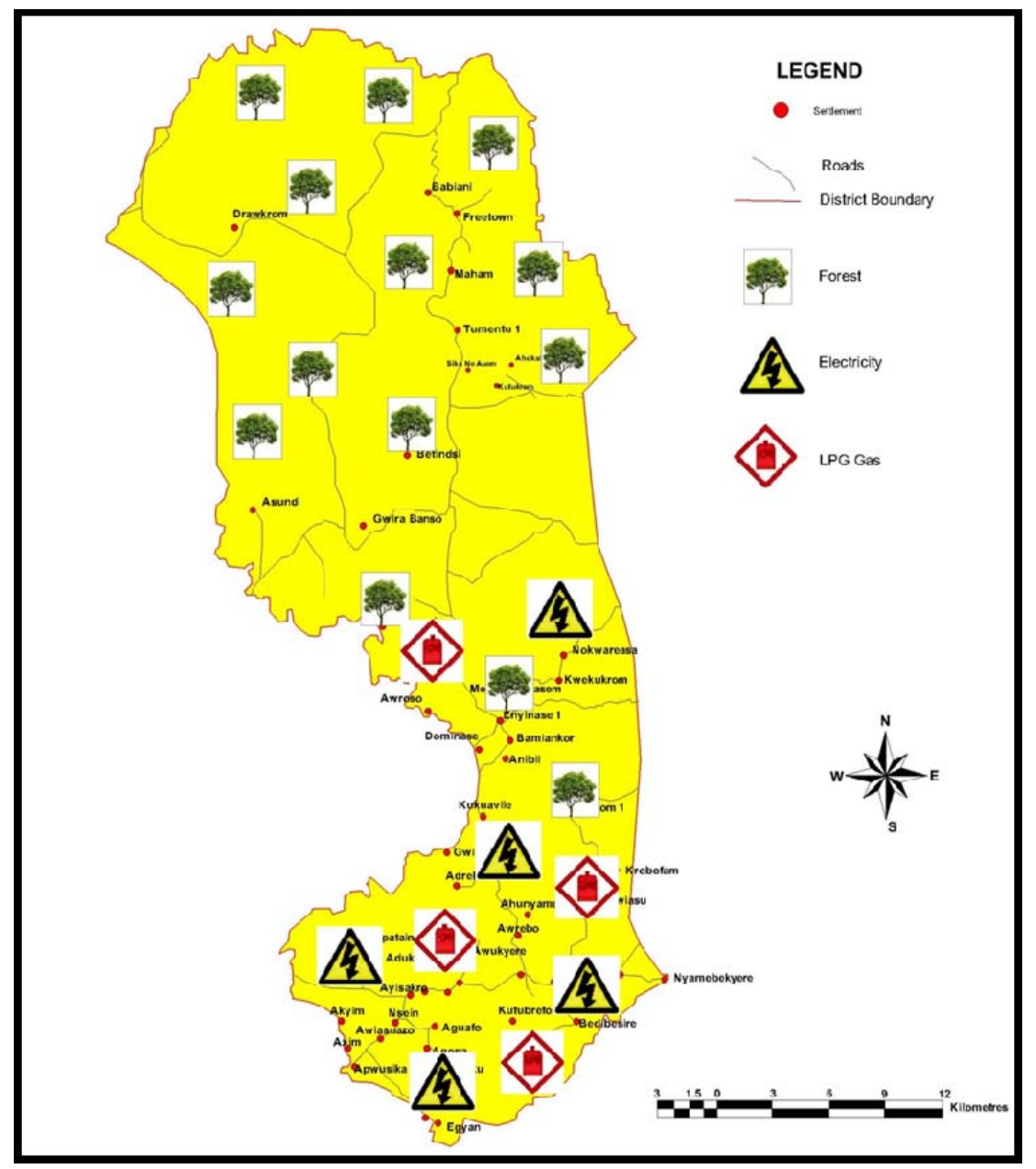

Figure 3: Spatial distribution of Energy resource availability Source: Adom-Opare, 2012

It could be said here that; spatial attributes of energy resources have serious bearings on how energy and supplied and consumed in each spatial context. While one context will increase more than proportionately in demand and supply, the other will lurk behind and the essence of sustaining energy will not have been achieved. Hence within the current context of sustainable energy, having large differences in resource availability in different spatial locations affects the extent to which energy demand and supply will be sustainable. But this is the case in every part of the world and hence there has been the need for resource and information sharing among the various spatial settings in order to support energy.

\section{Time Dimension}

Time is very important in understanding what happens now and in the future. Current demand and supply as well as future (short, medium and long term) demand and supply play major roles in ensuring a sustainable energy. Current energy supply and demand patterns were projected using a growth rate of fuel consumption over a period between 20 years. Two scenarios were designed. Scenario one uses the growth rate obtained from the survey and scenario two is based on the growth rate as used by the national energy trends of consumption. 
These two scenarios are used because, in national documents, the rate of fuel wood (3\%) and charcoal $(2.5 \%)$ annual growth (Energy Commission, 2006) is lower when compared to the rates obtained from the household surveys in rural NEMA which were $30 \%$ and about $25 \%$ respectively.

The assumptions guiding the projections are that (1) all socio-economic and physical characteristics will remain the same over the projection period of 20 years (2012-2032), (2) the population growth will grow exponentially over 20 years, and (3) household size will remain the same. The projections are detailed in annex 5 , however the growth projections are graphed in the following sections.
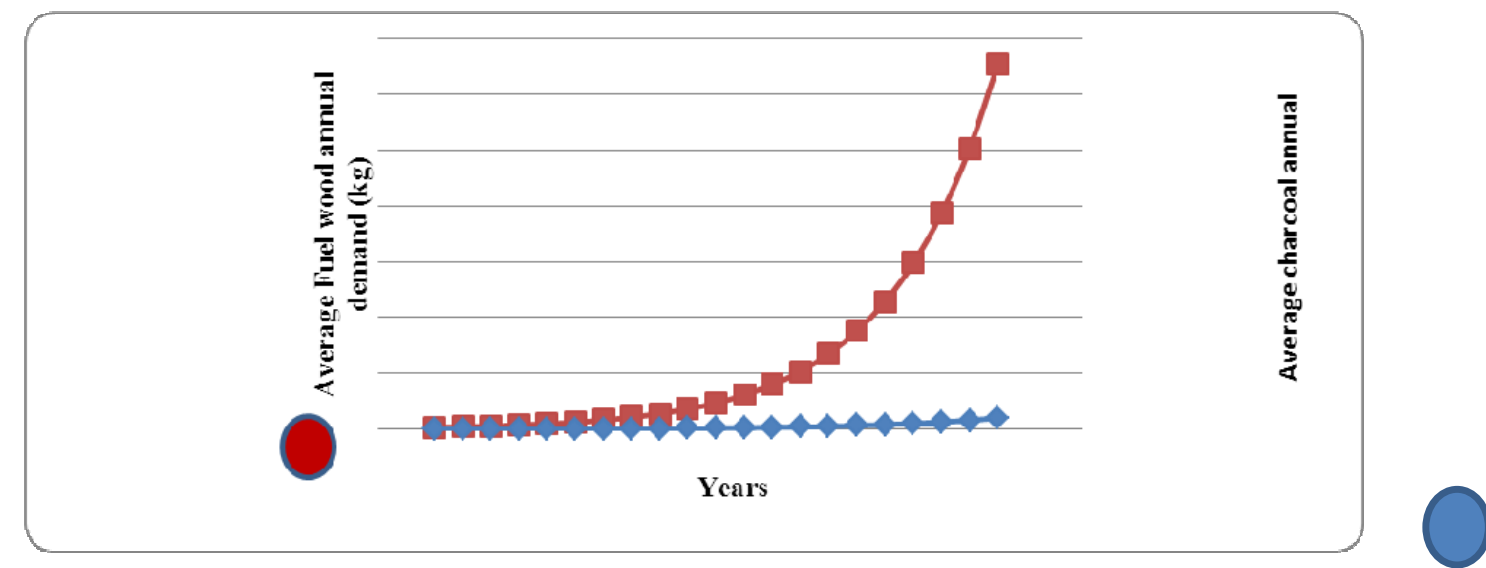

Figure 4. Energy demand forecast with household survey growth rate

Source: Adom-Opare, 2012

In scenario 1, average annual household energy consumption for both fuel wood and charcoal is expected to increase from $68,814.80 \mathrm{~kg} /$ annum and $4,706.32 \mathrm{~kg} /$ annum in to 13 million $\mathrm{kg} /$ annum and $408,208.19 \mathrm{~kg} /$ annum respectively by the end of 2032 . When this is compared to the forecast in scenario 2 , it is seen that the average annual household energy consumption increases from $68,814.80 \mathrm{~kg} /$ annum and $4,706.32 \mathrm{~kg} /$ annum to $113,311.12 \mathrm{~kg} /$ annum and $8,458.87 \mathrm{~kg} /$ annum for fuel wood and charcoal respectively by the end of 2032 .

This notwithstanding, the expected consumption rate for both fuel wood and charcoal after 20 years is still high in both scenarios (13.4million $\mathrm{kg}$ and $121,769.9 \mathrm{~kg}$ for scenarios 1 and 2 respectively); hence decision makers need to seriously consider the planning for future energy management.

In projecting for the supply-side the annual growth rates used as identified from the survey were $4.7 \%$ and $0.3 \%$ for fuel wood and charcoal respectively. However, after 2020 there will be an annual reduction in supply in both fuel wood and charcoal by $1 \%{ }^{9}$ because it is assumed that by 2020 the national rural electrification programme would have been implemented and all rural communities will have access to electricity. This assumption was also based on the fact that, people are more willing to add modern energy sources to their regular residential energy consumption but not in the near future, as revealed by the survey.

\footnotetext{
9 This was based on qualitative data obtained from household interviews and energy suppliers; averages of assumed reduction by the interviewed energy suppliers were compiled to achieve this average
} 


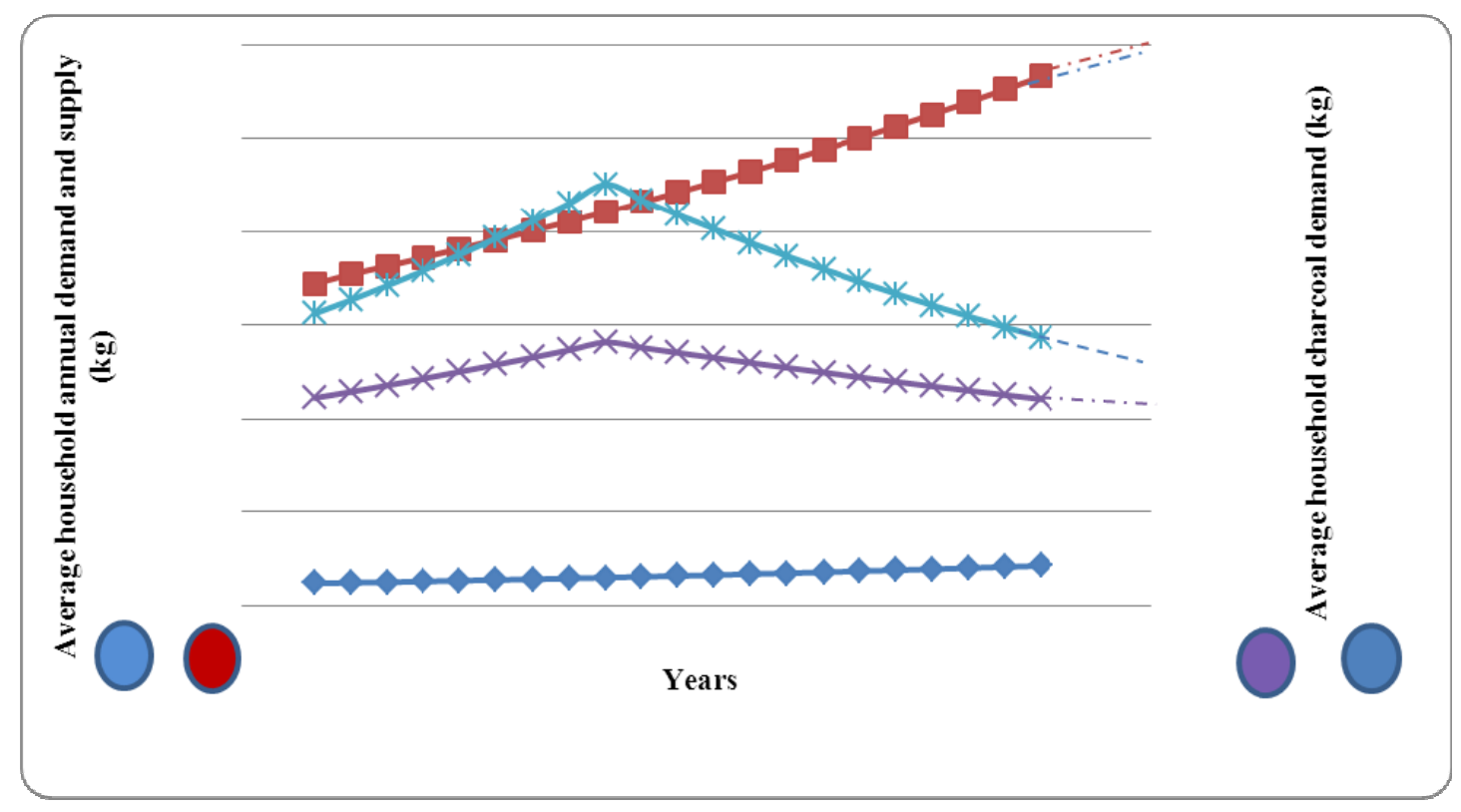

Figure 5: Demand and Supply of Energy

Source: Adom-Opare, 2012

The projections show that, though in the short and part of medium term, energy supply can support demand, it becomes over stretched when the time periods enter into the long term. It is seen that, in the first forecast scenario, from the beginning of the period, fuel wood demand is ahead of the supply and as the years move on, the gap becomes large. However, considering charcoal, it is realized that not until the year 2024, charcoal supply has been ahead of its demand. The peak year for charcoal is in 2023 where supply stood at approximately $62,000 \mathrm{~kg} /$ annum and demand stood at approximately $55,000 \mathrm{~kg} /$ annum.

The regression function for the forecast curves were computed and the coefficients of determination $\left(\mathrm{R}^{2}\right)$ for charcoal and fuel wood demand over the forecast period are 0.99 and 0.97 respectively. This means that $99 \%$ and $97 \%$ (for charcoal and fuel wood respectively) of the total variation in energy demand can be explained by data obtained from the field and also the linear relationship between the forecast period and the demand; however, the other 1 and $3 \%$ of the total variation in demand remains unexplained. The $\mathrm{R}^{2}$ for the supply side were 0.12 and 0.04 for charcoal and fuel wood respectively; this meaning the data obtained can only explain $12 \%$ and $4 \%$ of total variations in charcoal and fuel wood supply respectively.

\section{Adaptive Capacity}

Given the numerous difficulties in the uncertain nature in understanding adaptive capacity, using the current adaptation of social systems becomes an acceptable proxy for the system's capacity to adapt in the future (Cooper et al., 2008; Fussel and Klein, 2006; Challinor et al., 2009; cited in Below et al., 2012). Five features that determine the adaptive capacity of communities or regions are discussed in detail: economic wealth, technology, information and skills, infrastructure, and institutions and equity (Smit et al., 2001). In all these determinants, a rating scale of 1-5 using Likert scale (with 1 being the least and 5 the highest 
quality; and an average rate from 0.0 being no quality in determinant and 1.0 being perfect quality in determinant) was used to rate the quality its possess in aggregate adaptive capacity.

\section{The Range of Available Technological options for Adaptation}

The range of available technology in rural NEMA to support energy and help the rural communities in extreme scenarios could include access electricity and other modern energy markets, example LPG, solar technologies among others. However, based on the study it was realised that, about $85 \%$ of selected communities were lacking in technological options to support adaptation to extreme conditions of climate; refer to table 4.10 for details on access to certain facilities in all selected communities.

From the rating scale, which was averaged from interviewed households and opinion leader, it showed an average rate of 0.15 which shows a very low quality of technological support to adaptation in these communities.

\section{The Availability of Resources and their Distribution across the Population}

This deals with both economic and physical resources and equity issues; large access to resources and evenly distribution across a geographic scope of interest are key in determining the adaptive ability of communities to changes in climate. With respect to physical availability of resources for fuel wood and charcoal, it was seen from the study that, over 30,000 hectares of off-forest reserve were available as a natural resource and energy extraction and a good supportive determinant for adaptive; however, when the demand supply forecast is referred, it could be seen that this resource will not be that supportive in the long (see section 5.3.6.1). Economically, it can be said here that, given an average monthly household income of GHS 109.3, households the case communities could be said to be earning a little above the national average for rural households of GHS 101.4 (GLSS 5, 2008). Notwithstanding, this monthly average is still not enough to cater for an average household size of six (6).

On the case of equity, the spatial dimension discussed earlier have extensively provided details on spread of energy resources - refer to section 5.3.2 above; this showed that most people $(51 \%)$ were located within low access zones. Put together, the average ratings from the interviewed sample showed a rating of 0.67 which indicates that quality of available resources and its distribution to support adaptation to changes to climate is high.

\section{The Structure of critical institutions}

The investigated relevant institutions included the municipal assembly, Electricty Company of Ghana (ECG), Meteorological Survey Department, Lands commission, Forestry Service Department, and the Environmental Protection Agency (EPA). The institutional survey showed that these institutions worked independently of each other and there was no coordination in terms of energy issues and policy. Also, it was realised that, the MoEn is much centralised and operates from the head office in Accra with no decentralised unit in the district assemblies. It was raised in an interview during the field study that, since the MoEn is centralised, issues concerning energy in the municipal assembly was weakly handled by 
district authorities. This has made the holistic structure of the critical institutions in the area very weak. As a result, the average of rating scores by the interviewed sampled showed a rate of 0.25 .

\section{The Stock of Human capital, including education and personal security}

Human capital represents a very important determinant in adaptive capacity of rural communities. A literate society is an asset and development grow faster compared to the illiterate society. Based on the survey, it was realised that majority $(52 \%)$ of the adult age cohort had obtain basic educational level and about $11 \%$ had obtained above secondary education; while about $19 \%$ were illiterates. Given the fact that more adults were literates and had obtained basic education the rating scale for this determinant was at 0.87 .

\section{The Stock of social capital, including the definition of property rights}

The ability to collectively agree and achieve results becomes a strong qualitative measure of adaptive capacity to extreme climate change impacts. It was realised from the study that, the acquisition of certain infrastructure by collective means was very evident in most of the communities. In all the communities, there had been collective efforts in constructing drains and toilet facilities as well as feed stock warehouse for their farm produce. The interviewed sample rated this determinant at an average of 0.77 .

\section{The Public's perceived attribution of the source of stress and the significance of exposure to its local manifestations}

It is very common for the locals of an ecosystem to be able to identify sources of climate change stresses and its direct effects to their ecosystem. This determinant becomes important when people are able to identify these stresses and its potential or current damage to their livelihoods. Knowing this, it puts inhabitants in the best position to either adapt or mitigate these stress sources. Knowing these factors, the survey conducted among the sample households and opinion leaders showed that, people in rural NEMA were moderately able to identify stress source and its exposure to the local livelihood. The average score was thus 0.45 from the interviewed sample.

In conclusion, aggregating these determinants of adaptive capacity showed an average score of 0.52 . This means that, rural NEMA could cope adequately with climate change impacts within the energy mix. However, with increasing demand and limited supply, this adaptive capacity is threatened in the medium and longer terms. In summary, it could be said that, these six determinants are used to gain better understanding and a clear picture of how capable rural communities are adapting amidst climate change within the energy context.

\section{Equating Results into the SE Framework}

It has been realized that the use of fuel wood and charcoal in rural areas has consequences on the environment and human health and ultimately, climate change. On the environmental side, fuel wood and charcoal consumption pose threats in a form of carbon emissions. Though Ghana and most African countries are not heavy carbon emitters, it becomes very important to consider this when fuel wood and charcoal burning is one major source of residential and 
industrial energy resource. From the study, household and industrial/commercial fuel wood and charcoal consumption, emitted 24,171 tCO2/year and the net carbon capture ${ }^{10}$ was 112 billion tCO2/year. The balance between carbon emitted and capture provides an indication of more room for carbon sequestration in the area and its environs; however high growth in fuel consumption coupled with increasing forest reduction and water evaporation (refer to section 4.6.3 on data on evaporation) presents a case for concern over the years. Comparing this to national level, it is realized that, Ghana's carbon emission rate is 8.6million tCO2/year (World Bank, 2008). Data on carbon sequestration and current carbon emissions is very inadequate and not available hence limiting the ability to compare and take policy actions.

Based on the indicators discussed, it is very clear, from an aggregated point of view, that the current use of fuel wood and charcoal is less likely to be sustainable within the short, medium and long-term periods. Firstly, considering how affordable energy is to households and businesses, it is seen that current energy use is not very affordable to the minimum earners and this was measured by the energy burden of $42 \%$. Secondly, accessibility to the energy sources was increasingly decreasing. The surface accessibility analysis was used here, and it showed that $51 \%$ of the population were within low and least access zones to energy sources. Thirdly, considering how reliable fuel wood and charcoal is, it was realized that, current energy use is more secured (with average utility rating score of 0.49 ) than adequate (with an average utility rating score of 0.59 ).

In addition, the spatial distribution of resources and how equitable these resources are distributed were considered under SE. It was realized that, resources (natural and man-made) were not equitably distributed with large gaps between different geographical areas in terms of infrastructure and natural resources. Under time factors, it was realized that there will be two possible equilibriums between charcoal supply and demand in the years 2016 and 2023; but beyond 2023, demand exceeds supply. Looking at fuel wood, it is realized that over all the projected years demand exceeded supply. Only within the short term that, supply will be able to meet its demand. Finally, determining the adaptive capacity of the selected communities indicated that, an average rating score of 0.52 was recorded. This means that the people are more likely to be able to moderately adapt to climate change impacts but will face a more difficult challenge in the future against adaptation.

Looking at all the indicators of SE, it is possible to say that, the designed framework of SE will be able provide a more clearer and better understanding of sustaining energy demand and supply within the long term and help in the decision-making process of all SE issues.

\section{Concluding Remarks}

The paper has been able to identify that the amount of carbon emitted and the sequestered will not be sustainable in the near future. It thus went on further to explore the variables that make up the SE framework to try and answer the sustainability question. In addition, the paper identifies and discusses the critical issues related to SE. Despite this, however, there is

\footnotetext{
${ }^{10}$ Here, the forest cover was the only consideration since data on size of soil and water bodies of selected areas were not available from the secondary data.
} 
still room for further research to fully achieve the goals of SE. There should be an agreed valuation standard for the quantity of consumption and supply.

\section{References}

Adams, W. M. (2006). The IUCN Renowned Thinkers Meeting report: The Future of Sustainability: Re-thinking Environment and Development in the Twenty-first Century. Cambridge, UK, 29-31 January 2006. IUCN.

Africa Renewable Energy Access Programme (AFREA). (2011). Wood-Based Biomass Energy Development for Sub-Saharan Africa: issues and approaches. Washington, USA.

Amissah-Arthur J., \& Amonoo, J. A. (2004). Study of the Social and Poverty Impacts of Energy Interventions on Rural Communities in Ghana. Accra. KITE. pp. 3.

Amoateng, K. N. (2009). Climate Change in Ghana has become a Threat to Livelihoods. [Online] Available: http://www.modernghana.com/news/245464/1/climate-change-in-ghana-hasbecome-a-threat-t o-liv.html (May 31, 2011).

Asefa, S. (2006). The economics of sustainable development. Michigan: Western Michigan University Printing. USA.

Bangaly, S. et al. (1999). Energy as a tool for sustainable development for Africa, Caribbean and pacific countries (pp. 19-23). New York. UNDP.

Bhagavan, M. R., \& Karekezi, S. (1992). Energy for Rural Development (pp. 6-10, 71). London: Zed Books Ltd.

Blaikie, N. (2003). Analyzing Quantitative Data (pp. 12, 52, 65). London. SAGE Publications Ltd.

Boehm, R. G. (2008). United States Geography. Microsoft ${ }^{\circledR}$ Student 2009 [DVD]. Redmond, WA: Microsoft Corporation.

Brown, R. L. (1988). State of the World. Ontario, Canada: Penguin Books Canada Ltd.

Brown, R. L. (1992). State of the World. Baskerville, USA: Haddon Craftsmen Inc.

Burns, R. (2000). Introduction to Research Methods. Frenchs Forest, Pearson Education. CDU Library: 370.72 Burn.

DFID. (2002). Energy for the Poor; Underpinning the Millennium Goals (p. 7). London, DFID.

Durante, D., \& Sneller, T. (2005). Issue Brief: Energy Security (pp. 1- 4). New York: Ethanol Across America.

Energy and Development. (2005). Promoting Sustainable Renewables (pp. 10-17, 21-30.). New York: York Publications. USA.

Energy Commission. (2010). National Energy Statistics. Accra: Energy Commission. 
Energy commission. (2011). 2011 Energy (Supply And Demand) Outlook for Ghana. Accra, EC.

Energy Commission. (2012). Ghana Action Plan for Sustainable Energy for all by 2030. Accra, Energy commission.

ESMAP. (2009). Sustainable Energy Systems. [Online] Available: http://www.esmap.org/esmap/ (December 20, 2011).

Ghana Statistical Service. (2012). 2010 Population and Housing Census; Summary report of final results (p. 4.). Accra: Sakoa Press Ltd.

GLSS. (2008). Ghana Living Standards Survey Report of the Fifth Round (GLSS 5). Accra, Ghana Statistical Service.

IAEA. (2002). Assessing Energy needs for Rural Development (pp. 23-30, 37-43). New York: Zodiak Publications. USA.

IPCC. (1998). The Regional Impacts of Climate Change: An Assessment of Vulnerability. Special Report of IPCC Working Group II [Watson, R.T., M.C. Zinyowera, and R.H. Moss (eds.)]. Intergovernmental Panel on Climate Change, Cambridge University Press, Cambridge, United Kingdom and New York. pp 5-17.

IPCC. (2001). Climate Change 2001: Impacts, Adaptation and Vulnerability. IPCC Working Group II, Third Assessment Report. [McCarthy, J.J., O.F. Canziani, N.A. Leary, D.J. Dokken, and K.S. White (eds.)]. Cambridge: Cambridge University Press.

IPCC. (2009). IPCC Expert Meeting on Detection and Attribution Related to Anthropogenic Climate Change. Geneva, Switzerland, 14-16 September 2009. [Stocker, T., Field, C., Dahe, Q., Barros, V., Gian-Kasper P., Tignor, M., Midgley, P., and K. Ebi (eds.)] Geneva: IPCC Working Group I Technical Support Unit.

KITE. (2005). Development and Energy in Africa; Ghana country report. Accra, KITE.

KITE. (2008). Rural Sustainable Energy Systems in Ghana. Accra, KITE.

Kpeli-Semabia, D. (2011). Climate Change and Ghana: How much do Ghanaians know about the specifics of the effects of climate change on the country? Bigger picture, Africans? [Online] Future Challenges. Available: http://futurechallenges.org/web/guest/learn/climatechange/article/articles/CLIMATE+CHAN GE+AND+GHANA. (May 31, 2011).

Mosha, A. C. (2011). Climate change and poverty in Africa: an overview. In Takase, C. et al. (Eds.), Climate Change and poverty in Africa; Challenges and Initiatives (32nd ed., pp. 1-16). UNCRD: Japan.

Nkum Associates. (2003). How to do guide on District Poverty Profiling and Mapping. Accra: Local Government and Poverty Reduction Support Programme (LGPRSP).

Nzema East Municipal Assembly. (2006). Medium Term Development Plan. Nzema East. 
Nzema East Municipal Assembly. (2010). Medium Term Development Plan. Nzema East.

OECD. (2001). Towards a sustainable energy future (pp. 21-23, 76). France: OECD publications service.

Ogunlade, R. D. (2001). Sustainable energy and climate change; African perspective. In; Developing energy solutions for climate change. [Ogunlade, D. and Sparks, D (eds.) 2002]. Cape Town: EDRC. South Africa. pp 145-148.

Pandey, R. (2008). What should Energy Security mean to India? [Online] Available: http://www.asiantribune.com/?q=node/12072. (October 19, 2011).

Power, M. (2008). The Burden of FY 2008 Residential Energy Bills on Low-Income Consumers. Economic Opportunity Studies. Washington, USA.

Sims, R. E. H et al., (2007). Energy supply in Climate Change 2007: Mitigation. Contribution of Working Group III to the Fourth Assessment Report of the Intergovernmental Panel on Climate Change [B. Metz, O.R. Davidson, P.R. Bosch, R. Dave, L.A. Meyer (eds)], Cambridge University Press, Cambridge, United Kingdom and New York, NY, USA.

Smit, B. et al. (1999). The science of adaptation: a framework for assessment. Mitigation and Adaptation Strategies for Global Change (pp. 4, 199-213). Denver: Street Publications.

Smit, B. et al. (2000). An anatomy of adaptation to climate change and variability. Climatic Change (pp. 45, 223-251). Denver: Street Publications. USA.

Smithers, J., \& Smit, B. (1997). Human Adaptation to Climatic Variability and Change. Global Environmental Change.

Stoeglehner et al. (2011). Spatial dimensions of sustainable energy systems: new visions for integrated spatial and energy planning. Energy, Sustainability and Society, 1(2).

Tester, J. W. et al. (2009). Sustainable Energy. Michigan: MIT Press.

Thiam, N. (2009). Towards a sustainable energy system for Africa: An Africa perspective on energy security. In; Facing global environment change [Brauch, H. G. et al. (eds.)]. Geneva: Springer. Switzerland. pp. 445,449.

UNDP. (2000). World energy assessment. Energy and the challenge of sustainability. Geneva: UNDP.

United Nations Commission on Sustainable Development, (2001). Indicators of sustainable development: framework and methodologies. United Nations, New York.

United Nations. (2011). Increasing Access to energy services in rural areas - module 10. United Nations, New York.

Wilbanks et al. (2008). Effects of Climate Change On Energy in Energy Production and Use in the United States. USA. 


\section{Macrothink}

World Bank. (2008). Emissions trends in Ghana, Trading economics, [Online]. Available: http://www.tradingeconomics.com/ghana/co2-emissions-kt-wb-data.html (July 5, 2012).

World Bank, (2011). Energy and the World Bank, [Online]. Available: http://web.worldbank.org/WBSITE/EXTERNAL/TOPICS/EXTENERGY2/0,,contentMDK:2 2858145 pagePK:210058 piPK:210062 theSitePK:4114200,00.html (September 10, 2012).

World Energy Council. (2004). 2004 Survey of Energy Resources (20 th ed.). Amsterdam: Elsevier.

Yohe, G., \& Tol, R. S. J. (2002). Indicators for social and economic coping capacity -moving toward a working definition of adaptive capacity. Global Environmental Change. pp. 12, 25.

\section{ANNEXES}

\section{Annex 1: Reliability Indices}

\section{Adequacy Concept and Metrics}

1. Capacity: The ability of the system to provide sufficient throughput to supply final demand.

- Utilization: The degree to which the system is being utilized.

- Intermittency: The degree to which the system lacks constant levels of productivity.

2. Flexibility: The degree to which the system can adapt to changing conditions.

- Response to demand fluctuations: The extent to which the system is able to adapt to changes in quantity of energy demanded or location of demand.

- Ability to expand facilities: The degree to which the system can be easily and cost-effectively expanded.

\section{$\underline{\text { Security Concepts and Metrics }}$}

1. Infrastructure vulnerability: The degree to which the system is susceptible to disruption.

- Physical security: The degree to which physical assets/natural wood land forests in the system are secure against threats.

- Interdependencies: The degree to which the system relies on other infrastructure for its reliable operation, and is vulnerable to their disruption.

- Sector coordination: The degree to which coordination between stakeholders within the sector results in an effective exchange of information alerting stakeholders of emerging threats and mitigation strategies.

- History: The degree to which the system has been prone to disruption in the past. 
2. Consequences of infrastructure disruption: The degree to which a disruption in the system could cause harm.

- Economic impacts: The degree to which a disruption in the system might feasibly cause economic damage to industry stakeholders, agriculture, the government, or the public/inhabitants.

- Environmental impacts: The degree to which a disruption in the system might feasibly cause environmental damage.

- Human health impacts: The degree to which a disruption in the system might feasibly harm the health of producers and/or the public.

3. Energy security: The degree to which the primary energy system is secure against threats to global supply infrastructure.

Import levels: The degree to which primary energy supply relies on resources originating outside of the country.

- World excess production capacity: The degree to which excess production capacity exists in the global market and provides flexibility against demand fluctuations and supply outages.

- Price volatility: The degree of fluctuation in the average price of primary energy.

Annex 2: Household Average Monthly Income Levels

\begin{tabular}{|c|c|c|c|c|c|c|c|c|c|}
\hline \multirow{2}{*}{ Zones } & \multirow{2}{*}{ Communities } & \multicolumn{5}{|c|}{ Income (GHS) } & \multirow{2}{*}{$\begin{array}{c}\text { Community } \\
\text { Average } \\
\text { monthly exp. } \\
\text { (GHS) }\end{array}$} & \multirow{2}{*}{$\begin{array}{c}\text { Zone } \\
\text { Average } \\
\text { monthly } \\
\text { exp. (GHS) }\end{array}$} & \multirow{2}{*}{$\begin{array}{c}\text { Entire Study } \\
\text { Average } \\
\text { monthly } \\
\text { exp. (GHS) }\end{array}$} \\
\hline & & $<50$ & $50-100$ & $101-150$ & $151-200$ & $>200$ & & & \\
\hline \multirow{3}{*}{$\begin{array}{c}\text { Moist } \\
\text { deciduous } \\
\text { forest }\end{array}$} & Kutukrom & - & - & $60 \%$ & $10 \%$ & $30 \%$ & 155.0 & \multirow{3}{*}{120.0} & \multirow{9}{*}{109.3} \\
\hline & Gwira Banso & - & $30 \%$ & $40 \%$ & $10 \%$ & $20 \%$ & 150.0 & & \\
\hline & Gwira Eshiem & - & $20 \%$ & $40 \%$ & - & $40 \%$ & 55.0 & & \\
\hline \multirow{3}{*}{$\begin{array}{c}\text { Secondary } \\
\text { forest }\end{array}$} & Bamiankor & $50 \%$ & $50 \%$ & - & - & - & 50.0 & \multirow{3}{*}{100.0} & \\
\hline & Anibil & - & $100 \%$ & - & - & - & 100.0 & & \\
\hline & Dominase & - & $10 \%$ & $90 \%$ & & & 150.0 & & \\
\hline \multirow{3}{*}{$\begin{array}{l}\text { Coastal } \\
\text { savannah }\end{array}$} & Aguafo & $10 \%$ & - & $70 \%$ & - & $20 \%$ & 140.0 & \multirow{3}{*}{108.3} & \\
\hline & Nsien & - & $80 \%$ & $20 \%$ & - & - & 85.0 & & \\
\hline & Edelesuazo & - & $60 \%$ & $20 \%$ & - & $20 \%$ & 100.0 & & \\
\hline
\end{tabular}


Annex 3: Daily Expenditure on Fuel wood consumed by households

\begin{tabular}{|c|c|c|c|c|c|c|c|c|c|}
\hline \multirow[b]{2}{*}{ Zones } & \multirow[b]{2}{*}{ Communities } & \multicolumn{5}{|c|}{ Expenditure (GHS) } & \multirow{2}{*}{$\begin{array}{c}\text { Community } \\
\text { Average } \\
\text { daily exp. } \\
\text { (GHS) }\end{array}$} & \multirow{2}{*}{$\begin{array}{c}\text { Zone } \\
\text { Average } \\
\text { daily exp. } \\
\text { (GHS) }\end{array}$} & \multirow{2}{*}{$\begin{array}{c}\text { Entire } \\
\text { study } \\
\text { Average } \\
\text { daily exp. } \\
\text { (GHS) }\end{array}$} \\
\hline & & 0.0 & $\leq 0.5$ & $0.6-1.0$ & $1.1-2.0$ & $>2.0$ & & & \\
\hline \multirow{3}{*}{$\begin{array}{c}\text { Moist } \\
\text { deciduous } \\
\text { forest }\end{array}$} & Kutukrom & $90 \%$ & $10 \%$ & - & - & - & 0.30 & \multirow{3}{*}{0.45} & \\
\hline & Gwira Banso & $75 \%$ & $25 \%$ & - & - & - & 0.50 & & \\
\hline & Gwira Eshiem & $60 \%$ & $40 \%$ & - & - & - & 0.55 & & \\
\hline \multirow{3}{*}{$\begin{array}{c}\text { Secondary } \\
\text { forest }\end{array}$} & Bamiankor & $40 \%$ & $60 \%$ & - & - & - & 0.30 & \multirow{3}{*}{0.47} & \multirow{6}{*}{0.60} \\
\hline & Anibil & $70 \%$ & - & $30 \%$ & - & - & 0.65 & & \\
\hline & Dominase & $70 \%$ & $30 \%$ & - & - & - & 0.45 & & \\
\hline \multirow{3}{*}{$\begin{array}{c}\text { Coastal } \\
\text { savannah }\end{array}$} & Aguafo & $30 \%$ & $10 \%$ & $40 \%$ & - & $20 \%$ & 1.00 & & \\
\hline & Nsien & $60 \%$ & $30 \%$ & $10 \%$ & - & - & 0.60 & \multirow[t]{2}{*}{0.82} & \\
\hline & Edelesuazo & $50 \%$ & $40 \%$ & $10 \%$ & - & - & 0.85 & & \\
\hline
\end{tabular}

Annex 4: Daily Expenditure on Charcoal consumed by households

\begin{tabular}{|c|c|c|c|c|c|c|c|c|c|}
\hline \multirow{2}{*}{ Zones } & \multirow{2}{*}{ Communities } & \multicolumn{5}{|c|}{ Expenditure (GHS) } & \multirow{2}{*}{$\begin{array}{l}\text { Community } \\
\text { Average daily } \\
\text { exp. (GHS) }\end{array}$} & \multirow{2}{*}{$\begin{array}{c}\text { Zone } \\
\text { Average } \\
\text { daily exp. } \\
\text { (GHS) }\end{array}$} & \multirow{2}{*}{$\begin{array}{c}\text { Entire study } \\
\text { Average } \\
\text { daily exp. } \\
\text { (GHS) }\end{array}$} \\
\hline & & 0.0 & $\begin{array}{c}\leq \\
0.5\end{array}$ & $0.6-1.0$ & $1.1-2.0$ & $>2.0$ & & & \\
\hline \multirow{3}{*}{$\begin{array}{c}\text { Moist } \\
\text { deciduous } \\
\text { forest }\end{array}$} & Kutukrom & $5 \%$ & $90 \%$ & - & $5 \%$ & - & 0.50 & \multirow{3}{*}{1.5} & \\
\hline & Gwira Banso & - & - & $92 \%$ & $8 \%$ & - & 1.00 & & \\
\hline & Gwira Eshiem & $10 \%$ & - & - & $90 \%$ & - & 1.80 & & \\
\hline \multirow{3}{*}{$\begin{array}{c}\text { Secondary } \\
\text { forest }\end{array}$} & Bamiankor & - & - & - & $100 \%$ & - & 1.44 & \multirow{4}{*}{0.60} & \\
\hline & Anibil & - & - & - & $15 \%$ & $85 \%$ & 2.25 & & \\
\hline & Dominase & - & $30 \%$ & - & $10 \%$ & $60 \%$ & 2.55 & & \\
\hline \multirow{3}{*}{$\begin{array}{c}\text { Coastal } \\
\text { savannah }\end{array}$} & Aguafo & $40 \%$ & $50 \%$ & - & $10 \%$ & - & 0.50 & & 0.97 \\
\hline & Nsien & $10 \%$ & $10 \%$ & $40 \%$ & $30 \%$ & $10 \%$ & 1.43 & \multirow[t]{2}{*}{0.80} & \\
\hline & Edelesuazo & - & $70 \%$ & $30 \%$ & $10 \%$ & - & 0.60 & & \\
\hline
\end{tabular}


Annex 5: Average Annual Household Energy Demand forecast from 2012-2032

\begin{tabular}{|c|c|c|c|c|c|}
\hline \multirow{2}{*}{$\begin{array}{c}\text { Time } \\
\text { Dimensions }\end{array}$} & \multirow{2}{*}{$\begin{array}{c}\text { Projection } \\
\text { Years }\end{array}$} & \multicolumn{2}{|c|}{ Scenario 1} & \multicolumn{2}{|c|}{ Scenario 2} \\
\hline & & $\begin{array}{l}\text { Fuel wood } \\
(\mathrm{kg}) / \text { annum }\end{array}$ & $\begin{array}{l}\text { Charcoal } \\
\text { (kg)/annum }\end{array}$ & $\begin{array}{l}\text { Fuel wood } \\
(\mathrm{kg}) / \text { annum }\end{array}$ & $\begin{array}{l}\text { Charcoal } \\
\text { (kg)/annum }\end{array}$ \\
\hline \multirow{4}{*}{ Short term } & 2012 & $68,814.80$ & $4,706.32$ & $68,814.80$ & $4,706.32$ \\
\hline & 2013 & $89,459.24$ & $5,882.90$ & $70,879.24$ & $4,823.98$ \\
\hline & 2014 & $116,297.01$ & $7,353.63$ & $72,651.23$ & $4,968.70$ \\
\hline & 2015 & $151,186.12$ & $9,192.03$ & $74,467.51$ & $5,117.76$ \\
\hline \multirow{5}{*}{ Medium term } & 2016 & $196,541.95$ & $11,490.04$ & $76,329.19$ & $5,271.29$ \\
\hline & 2017 & $255,504.54$ & $14,362.55$ & $78,237.42$ & $5,429.43$ \\
\hline & 2018 & $332,155.90$ & $17,953.19$ & $80,193.36$ & $5,592.31$ \\
\hline & 2019 & $431,802.66$ & $22,441.48$ & $82,198.19$ & $5,760.08$ \\
\hline & 2020 & $561,343.46$ & $28,051.85$ & $84,253.15$ & $5,932.88$ \\
\hline \multirow{12}{*}{ Long term } & 2021 & $729,746.50$ & $35,064.82$ & $86,359.48$ & $6,110.87$ \\
\hline & 2022 & $948,670.45$ & $43,831.02$ & $88,518.46$ & $6,294.20$ \\
\hline & 2023 & $1,233,271.59$ & $54,788.78$ & $90,731.42$ & $6,483.02$ \\
\hline & 2024 & $1,603,253.07$ & $68,485.97$ & $92,999.71$ & $6,677.51$ \\
\hline & 2025 & $2,084,228.99$ & $85,607.46$ & $95,324.70$ & $6,877.84$ \\
\hline & 2026 & $2,709,497.69$ & $107,009.33$ & $97,707.82$ & $7,084.17$ \\
\hline & 2027 & $3,522,346.99$ & $133,761.66$ & $100,150.52$ & $7,296.70$ \\
\hline & 2028 & $4,579,051.09$ & $167,202.07$ & $102,654.28$ & $7,515.60$ \\
\hline & 2029 & $5,952,766.41$ & $209,002.59$ & $105,220.64$ & $7,741.07$ \\
\hline & 2030 & $7,738,596.34$ & $261,253.24$ & $107,851.15$ & $7,973.30$ \\
\hline & 2031 & $10,060,175.24$ & $326,566.55$ & $110,547.43$ & $8,212.50$ \\
\hline & 2032 & $13,078,227.81$ & $408,208.19$ & $113,311.12$ & $8,458.87$ \\
\hline
\end{tabular}

\section{Copyright Disclaimer}

Copyright for this article is retained by the author(s), with first publication rights granted to the journal.

This is an open-access article distributed under the terms and conditions of the Creative Commons Attribution license (http://creativecommons.org/licenses/by/3.0/). 